\title{
3-Hydroxyisobutyric Aciduria: An Inborn Error of Valine Metabolism
}

\author{
FANG-JONG KO, ${ }^{1}$ WILLIAM L. NYHAN, JON WOLFF, ${ }^{2}$ ḄRUCE BARSHOP, AND \\ LAWRENCE SWEETMAN" \\ Denartment of Pediatrics, University of California San Diego, La Jolla. California 92093
}

\begin{abstract}
Hydroxyisobutyric aciduria, a disorder of valine metabolism, has been found in a boy in whom the clinical picture was that of a typical organic acidemia with repeated episodes of ketoacidosis requiring admission to hospital and parenteral fluid therapy, along with impressive failure to thrive and chronic lactic acidemia. The excretion of 3-hydroxyisobutyric acid ranged from 170 to $390 \mathrm{mmol} / \mathrm{mol}$ of creatinine. The administration of valine increased this to $18700 \mathrm{mmol} / \mathrm{mol}$ of creatinine and reproduced the clinical picture of ketoacidosis. Concentrations of free carnitine were low, and esterified carnitine was elevated. Treatment with carnitine and a diet restricted in protein appeared to be beneficial. (Pediatr Res 30: 322 326,1991 )
\end{abstract}

Inborn errors of amino acid metabolism in which organic acid intermediates accumulate often present with life-threatening attacks of ketoacidosis. Lactic acidemia occurs in disorders of carbohydrate metabolism and abnormalities of electron transport as well as in the oxidation of pyruvate. It is the purpose of this report to describe a patient with an inborn error of valine metabolism in which the typical pictures of organic acidemia and lactic acidemia were associated with failure to thrive. 3Hydroxyisobutyric acid was found in large quantities in the urine and increased after the administration of valine.

\section{CASE REPORT}

S. B. was a 6-y-old Caucasian boy who was referred to the University of California San Diego Medical Center because of recurrent episodes of vomiting, acidosis, and dehydration.

He weighed $1.83 \mathrm{~kg}$ at delivery by elective cesarean section after a 37-wk gestation. He was the second child of healthy nonconsanguineous parents. An older sibling and a younger sibling were well. Dysmorphic features were noted at birth. His length was $45 \mathrm{~cm}$, and his head circumference was $27 \mathrm{~cm}$. The anterior fontanel appeared large, and the testes were undescended. A karyotype was normal. He was difficult to feed from the start and required gavage feedings for the 1st wk and was

Received October 8, 1990; accepted May 30, 1991.

Correspondence and reprint requests: Dr. William L. Nyhan, Department of Pediatrics (M-0609A), University of California. San Diego, La Jolla, CA 92093.

Supported by United States Public Health Service Grant No. HDO4608 from the National Institute of Child Health and Human Development and General Clinical Research Center Grant No. CR00527 from the Division of Research Resource National Institutes of Health. Bethesda. MD, and Grant No. NF 1-377 from the March of Dimes Birth Defects Foundation. White Plains, NY.

' Present address: Department of Pediatrics, Kaohsiung Medical College, Taiwan. R.O.C.

2 Present address: Department of Pediatrics, University of Wisconsin. Madison, WI 53705 .

3. Present address: Childrens Hospital of Los Angeles, 4650 Sunset Boulevard, Los Angeles, CA 90027. kept in the hospital for 2 wk. He was first admitted to hospital for vomiting and failure to thrive at 4 mo of age. A systolic ejection murmur was heard best in the aortic area, and an ECG indicated hypertrophy. At 3 y of age, he was admitted after a grand mal seizure and was found to have a serum concentration of bicarbonate of $8 \mathrm{mmol} / \mathrm{L}(8 \mathrm{mEq} / \mathrm{L})$. The $\mathrm{pH}$ was 7.26 . He responded to parenteral fluid and electrolyte therapy. He continued to have episodes of vomiting, lethargy, and acidosis requiring admission to hospital and parenteral fluid therapy. During these episodes, his breath smelled of acetone and the urine tested positive for large amounts of ketones. Kussmaul respirations were often observed. On at least one occasion, a blood sugar of $2.50 \mathrm{mmol} / \mathrm{L}(45 \mathrm{mg} / \mathrm{dL})$ was recorded. At 6 y of age, during such an episode, he was found to have a serum concentration of lactate of $6.77 \mathrm{mmol} / \mathrm{L}(61 \mathrm{mg} / \mathrm{dL})$ and a pyruvate of 0.33 $\mathrm{mmol} / \mathrm{L}(2.9 \mathrm{mg} / \mathrm{dL})$. The patient preferentially avoided proteincontaining foods, disliking meat, milk, and eggs.

Early development was delayed; he sat at $9 \mathrm{mo}$, walked at 18 mo and said only three words at $3 \mathrm{y}$. Developmental progress was satisfactory, and, ultimately, he was doing grade-level work in school appropriate for age, although he repeated the $3 \mathrm{rd}$ grade. At $3 \frac{1 / 2}{\text { y }}$ of age, he underwent a surgical repair of hypospadias and repair of a by then unilateral cryptorchidism. At 10 y of age, his intelligence quotient was 100.

Physical examination at 6 y of age revealed the multiple minor dysmorphic features. His face was small and triangular, and the philtrum was long. His ears looked small and low; the left measured $4.6 \mathrm{~cm}$, less than the 3 rd percentile for age, and the right was $4.8 \mathrm{~cm}$. There were bilateral simian creases and clinodactyly of the 5 th fingers. There was mild bilateral syndactyly of the $2 \mathrm{nd}$ and $3 \mathrm{rd}$ toes. His weight was $18.4 \mathrm{~kg}$ less than the 5 th percentile and was at the 50th percentile for a boy 3 y of age. His height was $119 \mathrm{~cm}$, at the 5 th percentile, and his head circumference was $51.5 \mathrm{~cm}$, at the 35th percentile. Neurologic examination was normal. There was a very soft systolic murmur at the left sternal border.

An EEG revealed a persistent vertex spike discharge and occasional generalized bursts of spike and wave activity consistent with a seizure disorder. The ECG was consistent with ventricular hypertrophy by voltage criteria, but an echocardiogram was completely normal. Muscle biopsy revealed a preponderance (68\%) of type I over type II (32\%) fibers, a reversal of the usual ratio, and electron microscopy revealed increased amounts of glycogen.

The hematocrit was 36 , and the leukocyte count was $4600 /$ $\mathrm{mm}^{3}$ with $52 \%$ polymorphonuclear forms and $48 \%$ lymphocytes. The concentration of sodium was 140 , potassium was 4 , chloride was 107 , and bicarbonate was $20 \mathrm{mmol} / \mathrm{L}(20 \mathrm{mEq} / \mathrm{L})$. The concentration of lactate was $2.02 \mathrm{mmol} / \mathrm{L}(18.2 \mathrm{mg} / \mathrm{dL})$, and that of pyruvate was $0.14 \mathrm{mmol} / \mathrm{L}(1.2 \mathrm{mg} / \mathrm{dL})$. The concentration of alanine was $730 \mu \mathrm{mol} / \mathrm{L}(6.5 \mathrm{mg} / \mathrm{dL})$. There was no $\beta$ alanine on amino acid analysis of blood or urine.

The excretion of lactate in the urine ranged from 1580 to 2380 $\mathrm{mmol} / \mathrm{mol}$ of creatinine (normal, $0-25$ ). A number of studies 
were carried out to investigate the mild lactic acidemia. Fasting for as long as $26 \mathrm{~h}$ was without acidosis or hypoglycemia Carbohydrate challenge tests were administered in a dose of $1 \mathrm{~g} /$ $\mathrm{kg}$ as a $20 \%$ solution 6 to $12 \mathrm{~h}$ postprandially. Blood was obtained at 0 and $45 \mathrm{~min}$. After glucose, the concentration of lactate rose from 2.0 to $2.66 \mathrm{~mol} / \mathrm{L}$ ( 18 to $24 \mathrm{mg} / \mathrm{dL}$ ) without a change in pyruvate. After fructose, the lactate rose from 1.54 to $4.42 \mathrm{mmol} /$ $\mathrm{L}$ ( 13.9 to $39.8 \mathrm{mg} / \mathrm{dL}$ ) and pyruvate rose from 0.08 to 0.19 $\mathrm{mmol} / \mathrm{L}(0.7$ to $1.7 \mathrm{mg} / \mathrm{dL})$. After alanine, the lactate rose from 1.06 to $3.08 \mathrm{mmol} / \mathrm{L}(9.5$ to $27.7 \mathrm{mg} / \mathrm{dL})$ and pyruvate rose from 0.006 to $0.17 \mathrm{mmol} / \mathrm{L}(0.5$ to $1.5 \mathrm{mg} / \mathrm{dL})$. After galactose, lactate rose from 2.53 to $4.53 \mathrm{mmol} / \mathrm{L}(22.8$ to $40.8 \mathrm{mg} / \mathrm{dL})$ and pyruvate rose from 0.11 to $0.16 \mathrm{mmol} / \mathrm{L}(1.0$ to $1.4 \mathrm{mg} / \mathrm{dL})$. After glycerol, lactate rose from 2.09 to $3.37 \mathrm{mmol} / \mathrm{L}$ (18.8 to $30.4 \mathrm{mg} / \mathrm{dL})$ and pyruvate rose from 0.14 to $0.18 \mathrm{mmol} / \mathrm{L}(1.2$ to $1.6 \mathrm{mg} / \mathrm{dL}$ ). On the basis of these data, he was given a diet low in simple sugars without obvious effect on his course or diminution in episodes of acute acidosis. Assay of cultured fibroblasts by Dr. Brian Robinson in Toronto revealed normal activity for pyruvate dehydrogenase, pyruvate carboxylase, and phosphoenolpyruvate carboxykinase, as well as the whole cell oxidation of $\left[1-{ }^{14} \mathrm{C}\right]$ pyruvate.

\section{MATERIALS AND METHODS}

Loading tests with isoleucine and valine were carried out $3 \mathrm{~h}$ postprandially in dosages of $100 \mathrm{mg} / \mathrm{kg}$. The patient was $91 / 2 \mathrm{y}$ of age and weighed $17.42 \mathrm{~kg}$. Blood was obtained at $0,1,2,3$, and $4 \mathrm{~h}$ for glucose, 3-hydroxybutyrate, and amino acids. Urine was collected in three 8-h samples. The patient was admitted to the General Clinical Research Center for these challenge tests after a number of months without intercurrent infection or episodes of acidosis. He was receiving at that time his normal diet, which was still fructose free but contained $2.5 \mathrm{~g} / \mathrm{kg}$ of protein and $103 \mathrm{kcal} / \mathrm{kg}$.

Concentrations of amino acids were determined by column chromatography on an automatic amino acid analyzer (1). Organic acids in urine were determined by liquid partition chromatography followed by gas chromatography-mass spectrometry (2) and by batchwise liquid partition chromatography on silicic acid followed by gas chromatography-mass spectrometry with automated identification and quantification of the trimethylsilyl derivatives (3). 3-Hydroxyisobutyric acid was quantified by using the unique fragment ion at $\mathrm{m} / \mathrm{z} 177$, and 3-hydroxybutyric acid was quantified by using the unique fragment ion at $\mathrm{m} / \mathrm{z} 199$ (4). Concentrations of carnitine in blood and urine were determined by the method of McGarry and Foster (5), and 3-hydroxybutyrate was quantified by the method of Maughan (6).

\section{RESULTS}

Organic acid analysis revealed the presence of substantial amounts of 3-hydroxyisobutyric acid in the urine. The amounts ranged from 170 to $390 \mathrm{mmol} / \mathrm{mol}$ of creatinine (normal, 2-33). The concentration of free carnitine in the plasma was $17.0 \mu \mathrm{mol} /$ $\mathrm{L}$, and that of the esterified carnitine was $11.2 \mu \mathrm{mol} / \mathrm{L}$. The urinary free carnitine was $2.3 \mathrm{mmol} / \mathrm{mol}$, and the esterified fraction was $64.7 \mathrm{mmol} / \mathrm{mol}$ of creatinine.

Loading with isoleucine was uneventful (Table 1). The patient's blood sugar was maintained between 4.16 and $4.77 \mathrm{mmol} /$ $\mathrm{L}$ ( 75 to $86 \mathrm{mg} / \mathrm{dL}$ ), and the serum 3-hydroxybutyrate remained in the range of 300 to $460 \mu \mathrm{mol} / \mathrm{L}$ (Fig. 1). Urinary organic acids were unchanged except for an increase in lactate to $1540 \mathrm{mmol} /$ mol of creatinine (normal, 0-25) and in 3-hydroxybutyrate to $1640 \mathrm{mmol} / \mathrm{mol}$ of creatinine (normal, 0-3) (Fig. 2). Urinary excretion of free carnitine was $0.43,0.54$, and $1.03 \mu \mathrm{mol}$ in each of the 8-h periods after the load; the esterfied carnitine was 18.99 , 14.75 , and $25.95 \mu \mathrm{mol}$.

On the following day, a load of valine reproduced the syndrome of clinical illness (Table 1). Two hours after administra- tion, the patient became flushed, lethargic, and diaphoretic, and he vomited. Ketonuria was prominent. The serum bicarbonate was $10 \mathrm{mmol} / \mathrm{L}$. He improved clinically after the administration of parenteral fluids containing sodium bicarbonate, but the bicarbonate rose slowly to $18 \mathrm{mmol} / \mathrm{L}$ in $8 \mathrm{~h}$ and to $24 \mathrm{mmol} / \mathrm{L} 5$ $\mathrm{h}$ later; he continued dry retching 2 more $\mathrm{h}$ after the onset of therapy. The serum concentration of glucose fell to $2.61 \mathrm{mmol} /$ $\mathrm{L}(47 \mathrm{mg} / \mathrm{dL})$ at $2 \mathrm{~h}$ (Table 1$)$, at which time the serum concentration of valine had risen to $1528 \mu \mathrm{mol} / \mathrm{L}(17.9 \mathrm{mg} / \mathrm{dL})$. The serum concentration of 3-hydroxybutyrate rose to $2640 \mu \mathrm{mol} /$ L. Urinary lactate rose to $30000 \mathrm{mmol} / \mathrm{mol}$ of creatinine and urinary 3-hydroxybutyrate rose to $18700 \mathrm{mmol} / \mathrm{mol}$ of creatinine. In addition, there were large amounts of dicarboxylic acids and 3-hydroxy acids in the urine, all concomitants of ketosis, as well as citric acid cycle intermediates.

On the basis of these data, treatment was initiated with a diet low in protein and $100 \mathrm{mg} / \mathrm{kg}$ of carnitine. The diet contained $0.75 \mathrm{~g} / \mathrm{kg}$ of protein and $100 \mathrm{kcal} / \mathrm{kg}$. This was associated with a marked reduction in the frequency and severity of attacks of acidosis. The patient's appetite did not permit an intake high in calories, and growth, though improved, remained slow. At 12 y of age, his weight of $21.9 \mathrm{~kg}$ was at the $50 \mathrm{th}$ percentile for a $6 \mathrm{y}$ old and his height of $129 \mathrm{~cm}$ was in the 50 th percentile for an 8 $y$ old. His head circumference of $54 \mathrm{~cm}$ was in the 50 th percentile for age

The effects of valine and isoleucine on the urinary organic acids are shown in Figure 1. The administration of valine led to a major increase in the excretion of 3-hydroxyisobutyrate. During the first $8 \mathrm{~h}$ after the load, the patient excreted $1888 \mathrm{mmol} /$ mol of creatinine and in the next $8 \mathrm{~h}$ the value was 2820 , considerable elevations over the $8 \mathrm{~h}$ before the load when he excreted $130 \mathrm{mmol} / \mathrm{mol}$ of creatinine. In contrast, in a control child (J. A.), the baseline level of excretion was only $20 \mathrm{mmol} /$ mol of creatinine and, after the same load of valine, it rose to 50 $\mathrm{mmol} / \mathrm{mol}$ of creatinine. In another control child (Table 2), the excretion of 3-hydroxyisobutyrate in $8 \mathrm{~h}$ after valine was only 18 $\mu \mathrm{mol}$ ( $26 \mu \mathrm{mol} / \mathrm{mol}$ of creatinine). Of the three control children given the same dose of valine, none became ill. Of two studied, neither increased the concentration of lactate, and, in all three, the blood sugar level was maintained (Table 1).

After valine, the excretion of 3-aminoisobutyrate by the patient increased in the second and third 8-h periods (Table 2). In contrast, after isoleucine, the amounts were too low to measure accurately. In contrast, this compound was undetectable after valine in the urine of two control individuals (J. A. and S. C.) and very slight in the third (Table 2).

In the patient, the valine load provided a total of $14.87 \mathrm{mmol}$. In the following $24 \mathrm{~h}$, he excreted $35 \%$ of this administered load, most of it in the form of 3-hydroxyisobutyrate, with the rest in 3 -aminoisobutyrate, acylcarnitine, and valine itself (Table 2). In the first 8 -h period, $12.5 \%$ of the load was excreted. In the comparable period, the control individual (Table 2) excreted only $1.4 \%$ and this was virtually all carnitine ester; this is what would be expected because that individual $(Z$. M.) has been reported (7) to have organic acidemia, and he was receiving treatment with carnitine. The baseline excretion of carnitine ester of this boy was $397 \mathrm{mmol} / \mathrm{mol}$ of creatinine, and the value after valine was 315 .

The clinically benign course after isoleucine was mirrored in the flat curves for glucose and lactate, whereas, after valine, the concentrations of glucose fell and those of lactate rose. The excretion of 3-hydroxyisobutyrate after isoleucine remained in the baseline range from 129 to $560 \mathrm{mmol} / \mathrm{mol}$ of creatinine (Fig. 1). The normal range in this laboratory is from 2 to $33 \mathrm{mmol} /$ mol of creatinine. The excretion of 3-aminoisobutyrate did not increase after isoleucine.

Ketosis, as reflected in 3-hydroxybutyrate excretion, was directly proportional $(r=0.958, p=0.0026)$ to 3 -hydroxyisobutyrate excretion after administration of both isoleucine and valine, and the excretion of urinary lactate was also positively 
Table 1. Effects of valine and isoleucine on concentrations in plasma and urine*

\begin{tabular}{|c|c|c|c|c|c|c|c|c|c|c|}
\hline & \multicolumn{5}{|c|}{ Isoleucine challenge $(\mathrm{h})$} & \multicolumn{5}{|c|}{ Valine challenge $(\mathrm{h})$} \\
\hline & 0 & 1 & 2 & 3 & 4 & 0 & 1 & 2 & 3 & 4 \\
\hline \multicolumn{11}{|l|}{ Patient (S. B.) } \\
\hline Glucose $(\mathrm{mmol} / \mathrm{L})$ & 4.77 & 4.33 & 4.33 & 4.16 & 4.39 & 3.83 & 2.78 & 2.61 & & \\
\hline Lactate $(\mathrm{mmol} / \mathrm{L})$ & 2.02 & & 2.09 & & & 2.00 & & 2.89 & & \\
\hline 3-OH-butyrate $(\mu \mathrm{mol} / \mathrm{L})$ & 300 & 320 & 360 & 460 & 390 & 1800 & & 2640 & & \\
\hline Bicarbonate $(\mathrm{mmol} / \mathrm{L})$ & & & & & & 22 & & 10 & & \\
\hline Valine $(\mu \mathrm{mol} / \mathrm{L})$ & & & & & & 333 & & 1528 & & \\
\hline Isoleucine $(\mu \mathrm{mol} / \mathrm{L})$ & 122 & & 686 & & & & & & & \\
\hline \multicolumn{11}{|l|}{ Control (J. A.) } \\
\hline Glucose $(\mathrm{mmol} / \mathrm{L})$ & & & & & & 4.33 & 4.61 & 4.61 & 4.66 & 4.39 \\
\hline Bicarbonate $(\mathrm{mmol} / \mathrm{L})$ & & & & & & 22 & 24 & 23 & 24 & 23 \\
\hline 3-OH-butyrate $(\mu \mathrm{mol} / \mathrm{L})$ & & & & & & 560 & 300 & 400 & 640 & 700 \\
\hline Valine $(\mu \mathrm{mol} / \mathrm{L})$ & & & & & & 243 & 1641 & 1363 & 1016 & 863 \\
\hline \multicolumn{11}{|l|}{ Control (S. C.) } \\
\hline Glucose $(\mathrm{mmol} / \mathrm{L})$ & & & & & & 5.16 & 4.50 & 4.88 & 4.44 & 4.11 \\
\hline Lactate $(\mathrm{mmol} / \mathrm{L})$ & & & & & & 2.12 & & 1.71 & & \\
\hline 3-OH-butyrate $(\mu \mathrm{mol} / \mathrm{L})$ & & & & & & 60 & 80 & 80 & 80 & 70 \\
\hline Valine $(\mu \mathrm{mol} / \mathrm{L})$ & & & & & & & & 1349 & & \\
\hline \multicolumn{11}{|l|}{ Control (Z. M.) } \\
\hline Glucose $(\mathrm{mmol} / \mathrm{L})$ & & & & & & 5.77 & 5.05 & 5.50 & 4.83 & 4.72 \\
\hline Lactate $(\mathrm{mmol} / \mathrm{L})$ & & & & & & 0.66 & & 0.66 & & 0.83 \\
\hline 3-OH-butyrate $(\mu \mathrm{mol} / \mathrm{L})$ & & & & & & 180 & 80 & 175 & 220 & 460 \\
\hline Bicarbonate $(\mathrm{mmol} / \mathrm{L})$ & & & & & & 24 & 25 & 27 & 25 & 27 \\
\hline Valine $(\mu \mathrm{mol} / \mathrm{L})$ & & & & & & 74 & 1554 & 1311 & 1067 & 889 \\
\hline
\end{tabular}

*J. A. and S. C. were both patients under study for recurrent episodes of acidosis in whom no metabolic abnormality was found. Z. M. was a boy with a disorder of isoleucine metabolism in whom the assay for 2-oxothiolase was normal but the fibroblast conversion of ${ }^{14} \mathrm{C}-2-\mathrm{methylbutanoate}$ to macromoles was abnormal (7).
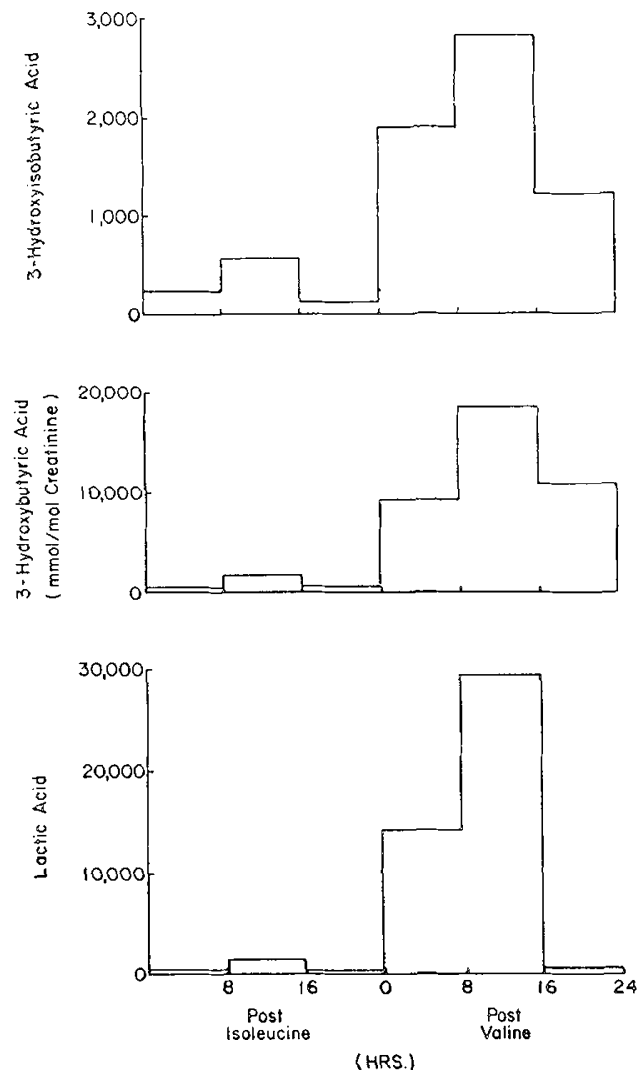

Fig. 1. The effects of valine and isoleucine on the urinary excretion of 3-hydroxyisobutyric acid, lactic acid, and 3-hydroxybutyric acid.

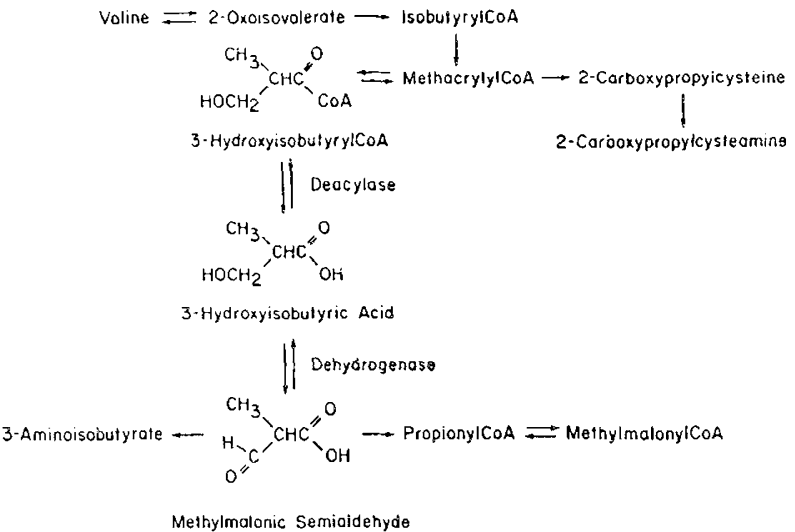

Fig. 2. Pathway of catabolism of valine.

correlated $(r=0.935, p=0.006)$ with 3-hydroxyisobutyrate excretion.

\section{DISCUSSION}

The clinical phenotype of this patient was typical of disorders of organic acid metabolism, the hallmark of which is the occurrence of recurrent episodes of vomiting, ketosis, and acidosis leading to dehydration and lethargy and requiring admission to hospital and vigorous resuscitation with large amounts of fluids containing sodium bicarbonate. Secondary lactic acidemia is common in such acute episodes of organic acidemia, but this patient had consistent elevations of blood and urinary concentrations of lactate and alanine. The lactic acidemia was usually mild, and the anion gap was sometimes normal; however, anion gaps were observed as high as 22 and 27 (defined as $\mathrm{Na}-\mathrm{CO}_{2}$ $+\mathrm{Cl})$. The normal should approximate 15 . Gluconeogenesis and the oxidation of pyruvate in vitro could not be shown to be disturbed. However, the lactic acidemia was regularly accom- 
Table 2. Disposition of valine load

\begin{tabular}{ccc}
$\frac{\text { Urinary excretion }}{\mu \mathrm{mol}} \mathrm{mmol}$ & $\begin{array}{c}\% \\
\text { Administered } \\
\text { valine }\end{array}$ \\
\hline
\end{tabular}

Patient S. B. (dose $14.87 \mathrm{mmol})$

Firsl 8 h

Valine $\quad 18.89$

3-Hydroxyisobutyrate $\quad 1820.00$

3-Aminoisobutyratc trace

Carnitine ester $\quad 20.64$

Total $8 \mathrm{~h}$

Second $8 \mathrm{~h}$

Valine

3-Hydroxyisobutyrate

3-Aminoisobutyrate

Carnitine ester

Total

Third $8 \mathrm{~h}$

Valine

3-Hydroxyisobutyrate

3-Aminoisobutyrate

Carnitine ester

Total $8 \mathrm{~h}$

Total $24 \mathrm{~h}$

$1.86 \quad 12.5$

16.49

2035.00

3.31

47.16

2.10

14.1

16.68

1169.00

6.11

129.36

$\begin{array}{rr}1.32 & 8.9 \\ 5.28 & 35.5\end{array}$

Patient Z. M. (dose $16.36 \mathrm{mmol}$ )

First 8 h

Valine

1.37

3-Hydroxyisobutyrate $\quad 17.86$

3-Aminoisobutyrate $\quad 0.34$

Carnitine ester $\quad 216.41$

Total $8 \mathrm{~h}$

0.24

panied by the concomitants hyperalaninemia and lactic aciduria. The highest blood alanine recorded was $1259 \mu \mathrm{mol} / \mathrm{L}$. The urinary lactate was usually 100 times normal, and blood lactates as high as $6.8 \mathrm{mmol} / \mathrm{L}$ were recorded. The elevation of plasma and urinary lactate in response to the administration of valine was striking. The level of urinary lactate increased in proportion to the accumulation of 3-hydroxyisobutyric acid. For these reasons, this disorder should be considered in the differential diagnosis of chronic lactic acidemia.

Failure to thrive and anorexia, other features of the presentation, are also typical of organic acidemia. Treatment with a diet restricted in protein and with carnitine led to an appreciable reduction in the frequency and severity of episodes of acidosis. However, anorexia was continuing and the patient's height and weight remained considerably below the norms for age. The occurrence of features of the Russell-Silver syndrome is further evidence for the nonspecific nature of these dysmorphic features (8).

Reproduction of the episode of acute illness by the administration of valine and the accumulation of 3-hydroxyisobutyric acid indicate that this is a disorder of valine catabolism. The conditions, $3 \mathrm{~h}$ postprandial, were the same for the valine and isoleucine loads. There is nothing in the record that explains the fact that the blood 3-hydroxybutyrate at time zero was 6 times higher for the valine load than that from the isoleucine load the previous day. The patient looked no different clinically. On the other hand, unexplained, or even cryptic, ketosis is common in this disorder, in which the worst consequence is the development of ketosis. The valine load could be followed for only $2 \mathrm{~h}$ because of the acute illness of the patient, which required intervention.

The pathway of valine catabolism is shown in Figure 2. The absence of accumulation of 3-hydroxypropionate, methylcitrate, or methylmalonate in the urine indicates that the defect lies before these steps in the pathway. Those steps are also shared with the catabolism of isoleucine, and the absence of reaction to isoleucine would also be against an abnormality at that level. An inborn error has been postulated in methacrylyl CoA hydratase (9) in a patient with multiple malformations who died at 3 mo of age, but the defect was found to be in 3-hydroxyisobutyryl CoA deacylase (10). That patient excreted the cysteine conjugates S-(2-carboxylpropyl)cysteine and S-(2-carboxypropyl)cysteamine. These compounds were not found in our patient. The fundamental defect could be in the 3-hydroxyisobutyrate dehydrogenase, which catalyzes the conversion of 3-hydroxyisobutyrate to methylmalonic semialdehyde, or in the conversion of the semialdehyde to propionyl CoA. We speculate that the defect is at the latter step. This would be consistent with the increase observed in the urinary excretion of 3-aminoisobutyrate after valine. Methylmalonic semialdehyde could not be found in urine samples, but this compound would be expected to be unstable in samples not treated promptly with reagents capable of making stable derivatives of the aldehyde. The interconversion of methylmalonic semialdehyde and 3-hydroxyisobutyrate would be expected to be under redox-controlled equilibrium and highly skewed toward 3-hydroxyisobutyric, as is the case with the interconversion 2-ethylhydracrylic acid and ethylmalonic semialdehyde. Propionate as the first metabolite in common in the catabolism of isoleucine and valine should be clearly distal to the metabolic defect, inasmuch as loading with isoleucine produced no illness and no increase in the excretion of 3-hydroxyisobutyrate or 3-aminoisobutyrate.

A patient with 3-hydroxyisobutyric aciduria has recently been reported (11). This patient had malformations, massive acidosis, and hypotonia and also excreted large amounts of 3-hydroxypropionic acid, ethylhydracrylic acid, and 3-hydroxyisovaleric acid. In our patient, small amounts of 3-hydroxypropionate and 3hydroxyisovalerate (23 to $126 \mathrm{mmol} / \mathrm{mol}$ of creatinine) were found in the urine after valine loading and the amounts were similar after isoleucine loading. All of these compounds increased after loading with valine in the patient recently reported (11). Therefore, it appears that this was a very different disorder. It is possible to miss the presence of 3-hydroxyisobutyric acid with many systems of organic acid analysis. In fact, in the analytic system previously in use in this laboratory (2), 3-hydroxyisobutyric acid could not be distinguished from 3-hydroxybutyric acid except by gas chromatography-mass spectrometry and, in the presence of ketosis when large amounts of 3-hydroxybutyric acid are excreted, it would not be recognized. Thus, this disorder should be included in the differential diagnosis of organic acidemia in which there is ketoacidosis.

The compounds along the pathway from isobutyryl CoA to methylmalonic semialdehyde or 3-aminoisobutyric acid would be expected to be in the form of the $\mathrm{S}$ isomers. Accumulated methylmalonic semialdehyde could undergo spontaneously oxoenol tautomerism yielding a racemic mixture of the $\mathrm{S}$ and $\mathrm{R}$ forms. Reduction would yield some (R)-3-hydroxyisobutyric acid and amination some (R)-3-aminoisobutyric acid. Therefore, determination of the nature of these compounds would be of considerable interest.

\section{REFERENCES}

1. Spackman DH, Stein WH, Moore S 1958 Automatic recording apparatus for use in the chromatography of amino acids. Anal Chem 30:1190-1206

2. Sweetman L 1984 Qualitative and quantitative analysis of organic acids in physiologic fluids for diagnosis of the organic acidurias. In: Nyhan WL (ed) Abnormalities in Amino Acid Metabolism in Clinical Medicine. AppletonCentury-Crofts, Norwalk. CT. pp 419-453

3. Hoffmann G. Aramaki S, Blum-Hoffmann E, Nyhan WL, Swectman L 1989 Quantitative analysis for organic acids in biological samples: batch isolation followed by gas chromatographic-mass spectrometric analysis. Clin Chem $35: 587-595$

4. Swectman L 1991 Organic acid analysis. In: Hommes FA (ed) Techniques in Diagnostic Human Biochemical Genetics. A Laboratory Manual. WilcyLiss, New York, pp 143-176

5. McGarry JD, Foster DW 1980 Regulation of hepatic fatty acid oxidation and ketone body production. Annu Rev Biochem 49:395-420

6. Maughan RJ 1982 A simple, rapid method for the determination of glucose. 
lactate, pyruvate alanine, 3-hydroxybutyrate and acetoacetate on a single 20- $\mu$ l blood sample. Clin Chim Acta 122:231-240

7. Iden P. Middleton B, Robinson BH. Sherwood WG, Gibson KM, Sweetman L. Sovik O 1990 3-Oxothiolase Activities and $\left[{ }^{14} \mathrm{C}\right]-2-$ Methylbutanoic Acid Incorporation in Cultured Fibroblasts from 13 Cases of Suspected 3-Oxothiolase Deficiency. Pediatr Res 28:518-522

8. Jones KL 1999 Russell-Silver syndrome. In: Smith's Recognizable Patterns of Human Malformation. WB Saunders. Philadelphia, pp 88-89

9. Truscott RJW, Malegan D, McCairns E, Halpern B, Hammond J, Cotton
RGH, Mercer JFB, Hunt S, Rogers JG, Danks DM 1981 Two new sulphurcontaining amino acids in man. Biomed Mass Spectrom 8:99-104

10. Brown GK, Hunt SM, Scholem R, Fowler K, Grimes A, Mercer JFB, Truscot RM, Cotton RGH, Rogers JG. Danks DM $1982 \beta$-Hydroxyisobutyryl coenzyme A deacylase deficiency: a defect in valine metabolism associated with physical malformations. Pediatrics 70:532-538

11. Mienic LJ, Erasmus E 1990 Biochemical studies on a patient with a possible 3-hydroxisobutyrate dehydrogenase deficiency. 5th International Congress on Inborn Errors of Metabolism. Pacific Grove, CA, abstr OC2.7 